\title{
LNG-IUS: The best tool for non-surgical treatment of abnormal uterine bleeding and endometriosis
}

\author{
Keshav Ram Benipal ${ }^{1, *}$, Anita Pal ${ }^{2}$, Manish Thakur ${ }^{3}$, Anoop Sharma ${ }^{4}$, Atul Sharma ${ }^{5}$ \\ ${ }^{1}$ Senior Resident, ${ }^{2}$ Professor \& HOD, ${ }^{3}$ Junior Resident, ${ }^{4}$ Assistant Professor, ${ }^{5}$ Medical Officer, Dept. of Obstetrics and \\ Gynecology, ${ }^{\mathbf{1 , 2 , 3 , 4}}$ Indira Gandhi Medical College, Shimla, Himachal Pradesh, ${ }^{5}$ Deen Dayal Upadhayaya Hospital, Shimla, \\ Himachal Pradesh, India
}

*Corresponding Author:

Email: drbenipalkeshav@gmail.com

\begin{abstract}
Introduction: The levonorgestrel- releasing intrauterine system (LNG-IUS) is the best tool for the non-surgical treatment for uterine bleeding and endometriosis.

Materials and methods: Fifty-two women between the age $32-55$ years were studied over a period of three years.

Results: LNG-IUS caused 85\% decrease in the amount of menstrual blood loss at 6 month and complete amenorrhea at two years.

Conclusion: LNG-IUS was the best and effective to surgical management and other modes of medical treatment of abnormal uterine bleeding. The patient showed better compliance and satisfaction to the LNG-IUS.
\end{abstract}

Keywords: Levonorgestrel-releasing intrauterine system (LNG-IUS), Abnormal Uterine Bleeding (AUB).

\section{Introduction}

The abnormal menstrual complaint is one of the most common chief complaint in the reproductive agegroup of women. This is sometime incapacitating and worrisome for the women in social life. This is common cause for anemia. This hamper work productivity and affects quality of life. Previously potent orally active progestins become the mainstay in the treatment of abnormal uterine bleeding. The LNG-IUS (levonorgestrel-releasing intrauterine system), introduced by Schering- Oy, Finland. This releases in vitro $20 \mu \mathrm{g}$ of levonorgestrel per day. ${ }^{1,2}$ The amount of drug, after 5 years decreased to a rate of $14 \mu \mathrm{g}$ per day, which is clinically effective. ${ }^{3,4}$ Maximum amount of drug stays inside the uterus, and very small amount is absorbed into the blood. ${ }^{5}$ The LNG-IUS contains $52 \mathrm{mg}$ of levonorgestrel which is dispersed in polydimethylsiloxane. This also has reversible contraceptive benefit. It diminishes the menstrual blood loss and incidence of pelvic infection. ${ }^{6-8}$

In past, surgical removal of uterus was the definitive cure for the abnormal uterine bleeding but in modern era this has turned more towards a conservative therapy. ${ }^{9}$ However, many women are desirous of preserving their uterus and hysterectomy is also associated with ovarian failure occurring nearly four years earlier than expected. ${ }^{10}$

\section{Aims and Objectives}

To study levonorgestrel - releasing intrauterine system (LNG-IUS) as the best tool for non-surgical treatment of abnormal uterine bleeding and endometriosis.

\section{Materials and Methods}

52 women aged between 32 - 55 years with abnormal uterine bleeding participated in the study. These patients had presented with various menstrual complaints. We included women with uterine size upto 14 weeks. The Pap smear was normal study and malignancy ruled out on endometrial biopsy. The patients with acute pelvic inflammatory disease, anatomical uterine anomalies, submucosal fibroids which indent the uterine cavity, breast carcinoma and liver disease were excluded. The detailed history and examination done. The ultrasonography was done by vaginal route with $7.5 \mathrm{MHz}$ probe. Prior to LNG-IUS insertion patients were counseled regarding the altered bleeding pattern and cessation of menstruation in post insertion periods. LNG-IUS was inserted in the post menstrual period and oral progesterone (northisterone acetate) was added to relieve the symptoms for first two-three months.

LNG-IUS was inserted on outpatient basis except for 7 patients where it was inserted in operation theatre under sedation. These included patients having one or two caesarean sections, myomectomy, ectopic or other non-gynecological surgeries. The patient maintained menstrual calendar for 6 months and a follow up was done at 1 month, 6 months and then yearly for maximum 2 years. The patients were asked about relief of antecedent menstrual complaints. At every visit general, systemic, pelvic and breast examinations were done. Ultrasonography was done in specific patients like endometrial hyperplasia, leiomyoma and endometriotic cyst. LNG-IUS efficacy was measured as a subjective relief from antecedent symptoms. 


\section{Results}

There were 52 women participants. The patient's complain included menorrhagia in 35 (67.30\%), polymenorrhagia in $9(17.31 \%)$, menometrorrhagia in $5(09.62 \%)$ and dysmenorrhea in $3(5.77 \%)$ women (table 1).

\section{Table 1: Profile of Symptoms}

\begin{tabular}{|c|l|c|c|}
\hline S. No. & \multicolumn{1}{|c|}{ Symptoms } & Number & Percentage \\
\hline 1. & Menorrhagia & 35 & $67.30 \%$ \\
\hline 2. & Polymenorrhagia & 9 & $17.31 \%$ \\
\hline 3. & Menometrorrhagia & 5 & $9.62 \%$ \\
\hline 4. & Dysmenorrhagia & 3 & $5.77 \%$ \\
\hline
\end{tabular}

Table 2: Profile of comorbidities

\begin{tabular}{|c|l|c|c|}
\hline S. No. & \multicolumn{1}{|c|}{ Symptoms } & Number & Percentage \\
\hline 1. & Hypertension & 14 & $26.92 \%$ \\
\hline 2. & Diabetes & 10 & $19.23 \%$ \\
\hline 3. & Both & 5 & $9.61 \%$ \\
\hline 4. & Heart Disease & 4 & $7.69 \%$ \\
\hline 5. & Stroke & 2 & $3.84 \%$ \\
\hline 6. & Brain Tumour & 2 & $3.84 \%$ \\
\hline 7. & ITP & 1 & $1.92 \%$ \\
\hline 8. & Multiple vessel Disease & 1 & $1.92 \%$ \\
\hline
\end{tabular}

Table 2 shows incidence of comorbidities. Fourteen patients $(26.92 \%)$ had hypertension, 10(19.23\%) had diabetes and 5(9.61\%) both. Four (7.69\%) patients had heart disease, whereas 2(3.84\%) patients had stroke and brain tumour each. One (01.92\%) subject, each had ITP, multiple vessel disease which were medically unfit for major surgery.

Table 3: Profile of uterine size

\begin{tabular}{|c|l|c|c|}
\hline S.no & \multicolumn{1}{|c|}{ Uterine size } & Number & Percentage \\
\hline 1 & Normal & 30 & $57.70 \%$ \\
\hline 2 & 6-10 weeks & 11 & $21.15 \%$ \\
\hline 3 & $10-14$ weeks & 11 & $21.15 \%$ \\
\hline
\end{tabular}

Table 3 shows that 30(57.70\%) subjects had the normal uterine size, 11(21.15\%) had 6-10weeks size and 10-14 weeks uterine size respectively.

Table 4: Profile of ultrasound findings

\begin{tabular}{|c|l|c|c|}
\hline S.no & Ultrasound findings & Number & Percentage \\
\hline 1. & AUB-L & 18 & $36.61 \%$ \\
\hline 2. & AUB-M & 8 & $15.38 \%$ \\
\hline 3. & Endometriosis & 7 & $13.46 \%$ \\
\hline 4. & AUB-A & 4 & $7.69 \%$ \\
\hline
\end{tabular}

Table 4 shows the profile of ultrasound findings. 18(36.61\%) subjects had leiomyomas, $8(15.38 \%)$ subjects with endometrial hyperplasia, followed by $7(13.46 \%)$ subjects with endometriotic cysts and adenomyosis in $4(07.69 \%)$.

Table 5: Profile of bleeding patterns

\begin{tabular}{|l|c|c|c|c|}
\hline \multicolumn{1}{|c|}{$\begin{array}{c}\text { Bleeding } \\
\text { patterns }\end{array}$} & $\begin{array}{c}\text { 1 month } \\
(\mathbf{n = 5 2}) \\
\text { \%age }\end{array}$ & $\begin{array}{c}\text { 6 month } \\
(\mathbf{n = 5 2}) \\
\text { \%age }\end{array}$ & $\begin{array}{c}\text { 1year } \\
(\mathbf{n = 5 2}) \\
\text { \%age }\end{array}$ & $\begin{array}{c}\mathbf{2} \text { year } \\
(\mathbf{n = 5 2}) \\
\text { \%age }\end{array}$ \\
\hline Menorrhagia & $35(67.30 \%)$ & $15(28.84 \%)$ & $2(3.84 \%)$ & 00 \\
\hline $\begin{array}{l}\text { Moderate } \\
\text { flow }\end{array}$ & $14(26.93 \%)$ & $7(13.46 \%)$ & $4(7.70 \%)$ & 00 \\
\hline Spotting & $03(05.77 \%)$ & $23(44.24 \%)$ & $09(17.31 \%)$ & 00 \\
\hline Amenorrhea & 00 & $07(13.46 \%)$ & $37(71.15 \%)$ & $52(100 \%)$ \\
\hline
\end{tabular}


Table 5 shows bleeding pattern in all patients.There is progressive decrease in menstrual blood loss over a period of 1 month, 6month, 1 year and 2 years. Thirty five $(67.30 \%)$ patients had menorrhagia at 1 month, 23(44.24\%) spotting at 6 month. $37(71.15 \%)$ patients become amenorrheic at end of one year, whereas 52(100\%) patients at end of two years.

\section{Discussion}

LNG-IUS is a reversible contraceptive intrauterine device which is longacting. In our study, LNG-IUS use was associated with $85 \%$ symptomatic relief. The amount of menstrual blood loss is decreased significantly at 6 months and patients become amenorrhoeic by 2 years. The Results were comparable to other studies conducted in the past. ${ }^{11-15}$ LNG-IUS achieved endometrial regression in $92 \%$ of the cases with endometrial hyperplasia. One patient underwent hysterectomy on request despite regressed endometrium. The LNG-IUS is a viable alternative to hysterectomy. This is a cost-effective outpatient procedure. The studies conducted in the past also bear a similar implication. ${ }^{16-17}$ The patients with endometriotic cyst showed symptomatic relief and a progressive decrease in cyst size with disappearance at 2 years. The levels of CA- 125 also decreased at 6 months of insertion, suggesting that LNG-IUS has a significant effect on endometriotic lesion18-19. The efficacy of LNG-IUS was ascertained by subjective symptomatic relief and quality of life improvement. It is associated with improved psychological well-being.

The LNG-IUS is more effective in menorrhagia than oral drugs. ${ }^{20,21}$ The patient's satisfaction with LNG-IUS insertion was $96 \%$. The LNG-IUS was also inserted in women having various co-morbidities and who were medically unfit for major surgery. ${ }^{22,23}$

\section{Conclusion}

LNG-IUS has been found to be best and superior to other non-surgical and surgical treatment. It is well accepted and an effective in the medical treatment of abnormal uterine bleeding. LNG-IUS use had very good efficacy and patient become amenorrhoeic at 2 years. The patient had good compliance and excellent satisfaction. This reduced the amount of menstrual blood loss. It is a very good tool for women who have abnormal uterine bleeding and desire contraception. It is used safely in women who underwent prior abdominal major surgeries. LNG-IUS is the best and economical in its clinical-use. LNG-IUS is considered as medical hysterectomy. The side effects are less and mostly patients are fully satisfied, assurance may help to continue the device. This device is cost effective and improves women's quality of life than other modes of treatment. Our study concluded that LNG-IUS, the levonorgestrel releasing intrauterine system provides an excellent non-surgical treatment of abnormal uterine bleeding, which is reversible and spares fertility.

\section{References}

1. Fritz MA, Speroff L. Clinical gynaecologic endocrinology and infertility. $8^{\text {th }}$ ed. Intrauterine contraception. Philadelphia: Wolters Kluwer Lippincott Williams \& Wilkins; 2011. P. 1100

2. Luukkainen T, Allonen H, Haukkamaa M, Lahteenmake $\mathrm{P}$, Nilsson CG, Toivonen J, Five years experience with levonorgestrel- releasing IUDs, Contraception 33:139,1986

3. HildalgoMM, Hidalgo-Regina C, Bahamondes MV, Monteiro I, Petta CA, Bahamondes L. Serum levonorgestrel levels and endometrial thickness during extended use of levonorgestrel- releasing intrauterine system. Contraception 2009;80:84-9.

4. Seebar B, ziehr SC, Gschliesser A, Moser C, Mattle V, Segar C, et al. Quantitative levonorgestrel plasma levelsmeasurements in patients with regular and prolonged use of levonorgestrel-releasing intrauterine system. Contraception 2012;86:345-9.

5. TrusselJ, Nelson AL, Gates WJ, Hatcher RA, Polkar MS , Kowal D, et al. Contraceptive technology. (20th revised ed.) New York: Ardent Media; 2011.p147-91.

6. Sivin I, Stern J, Coutinho E, Mattos CER, EI Mahgoub S, Pavej M etal, Prolonged intrauterine Contraception: a seven yearsrandomized study of the levonorgestrel 20 micro gm/d(LNg20) and the copper T $380 \mathrm{Ag}$ IUDs, Contraception 44:473,1991

7. Toivonen J, LuukkainenT, Allonen H, Protective effect ifintrauterine release of levonorgestrel on pelvic infection: three years comparative experience of levonorgestrel and copper releasing intrauterine devices, Obstet Gynecol77:261,1991

8. Bilian X, Liying Z, Xuling Z, Mengchun J, Luukkainen $\mathrm{T}$, allonen $\mathrm{H}$, Pharmacokinetic and pharmacodynamic studies of levonorgestrel releasing intrauterine device. Contraception 41:353,1990.

9. Wright RC. Hysterectomy: past, present and future. Obstet Gynecol1969:33:560-3.

10. Farquhar C, Sadler L, Harvey SA, Stewart AW. The association of hysterectomy and menopause: a prospective cohort study. BJOG. 2005;112(7)956-62.

11. Gunes M, Ozdegirmenci O, Kayikcioglu F, Heberal A, Kaplan M.The effect of levonorgestrel- releasing intrauterine system on uterine myomas . A 1 year follow up study. J Minim Invasive Gynecol2008;15:735-8

12. Grigorieva V, Chen-Mok M, tarasova M, Mikhailov A. Use of levonorgestrel- releasing intrauterine system to treat bleeding related to uterine leiomyomas. FertilSteril2003;79:1194-8.

13. 13. Cho S, Nam A, Kim H, Chay D Park K, Cho DJ, et al. Clinical effects of levonorgestrel- releasing intrauterine system in patients with Adenomyosis. Am J Obstet gynecol 2008;198:373.e1-7.

14. Sheng J, Zhang WY, Zhang JP, Lu D. The LNG-IUS study on adenomyosis. Contraceptiopn 2009;79:189-93

15. Desai RM. Efficacy of levonorgestrel- releasing intrauterine system for the treatment of menorrhagia due to benign uterine lesion in perimenopausal women. J. Midlife Health 2012;3:20-3.

16. Marjoribanks J, Lethaby A, Farquhar C. Surgery versesmedical therapy for heavy menstrual bleeding. Cochrane database syst Rev 2003: CD003855. 
17. Hurskainen R, Teperi J, Rissanen P, AltoAM, Grenman S, Kivela A, etal. Cilinical outcome and costs with the LNG releasing intrauterine system or hysterectomy for treatment of menorrhagia: Randomized trial five year follow up. JAMA 2004; 291:1456-63.

18. Winkel CA.Evaluation and management of women with endometriosis. Obstet Gynecol 2003; 102:397-408.

19. Matorras R, Ballesteros A, Prieto B, Ocerin I, Exposito A, Pijoan JI, et al. Efficacy of levonorgestrel- releasing intrauterine device in treatment of recurrent pelvic pain in multi treated endometriosis. J Reprod Med 2011;

20. 56:497-503.

21. Irvine GA, Campbell-Brown MB, Lumsden MA, Heikkila A, Walker JJ, Cameron IT. Randomized comparative trials of the levonorgestrelreleasing intrauterine system and northisterone for treatment of iodiopathic mmenorrhagia.BJOG1998;105:592-8.

22. Endrikat J, Shapiro H, Lukkari-Lax E, Kunz M, Schmidt W, Fortier M. A Canadian multicentre study comparing efficacy of the levonorgestrelreleasing intrauterine system to an oral contraceptive in a woman with idiopathic menorrhagia. J Obstet Gynecol Can 2009, 31:340-47.

23. Lukes AS, Reardon B, Arepally G. Use of levonorgestrelreleasing intrauterine system in a women with hemostatic disorders. Fertil Steril 2008; 90:673-7.

24. Grigorian OR, Grodnitskaya EE, Andreeva EN, Shestakova MV, Melnichenko GA, Dedov

II.Contraception in perimenopausal women with diabetes mellitus Gynecol Endocrinol 2006, 22:198-206. 